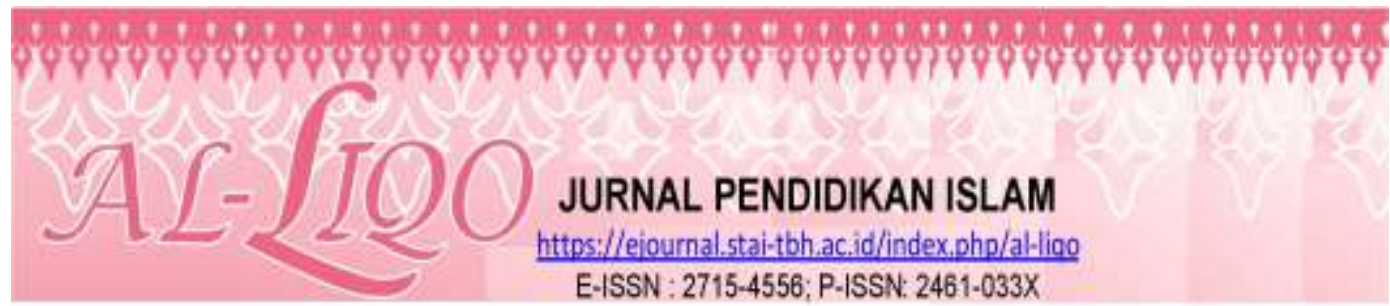

\title{
METODE TARGHIB DAN TARHIB DALAM PENDIDIKAN ISLAM
}

\author{
Syamsiah Nur ${ }^{1)}$ Hasnawati $^{2)}$ \\ ${ }^{1)}$ Dosen Tetap Program Studi Pendidikan Agama Islam STAI Auliaurrasyidin Tembilahan \\ Kabupaten Indragiri Hilir Propinsi Riau. Email : syamsiah.nur@stai-tbh.ac.id \\ ${ }^{2}$ Dosen Tetap Program Studi Pendidikan Agama Islam STAI Auliaurrasyidin Tembilahan \\ Kabupaten Indragiri Hilir Propinsi Riau. Email : hasnawati@stai-tbh.ac.id
}

\begin{abstract}
Abstrak
Targhib adalah janji yang disertai dengan bujukan dan membuat senang terhadap sesuatu yang mashlahat terhadap kenikmatan atau kesenangan akhirat yang baik dan pasti serta bersih dari segala kotoran yang kemudian diteruskan dengan melakukan amal shaleh dan menjauhi kenikmatan selintas yang mengandung bahaya dan perbuatan buruk atau maksiat kepada Allah SWT sedangkan Tarhib adalah ancaman atau intimidasi melalui hukuman yang disebabkan oleh terlaksananya sebuah dosa, kesalahan, atau perbuatan yang telah dilarang Allah SWT. Dari hal ini dapat disimpulkan bahwa Targhib - Tarhib merupakan strategi atau cara untuk menyakinkan seseorang terhadap kebenaran Allah SWT melalui janji-Nya yang melakukan amal shaleh berupa kenikmatan dialam akhirat dan ancaman bagi yang bermaksiat kepada-Nya. Metode ini diantara cara memberikan pelajaran dengan memberi dorongan (motivasi) untuk memperoleh kegembiraan bila mendapatkan sukses dalam kebaikan, sedang bila tidak sukses karena tidak mau mengikuti petunjuk yang benar akan mendapat kesusahan. Rumusan masalah yaitu; Bentuk-bentuk targhib-tarhib, Langkah-langkah metode targhib-tarhib, perbandingan antara targhib-tarhib dangan reward and punishment.
\end{abstract}

Kata Kunci : Metode Targhib, Tarhib, Pendidikan Islam

\section{PENDAHULUAN}

Hasil belajar siswa adalah perubahan yang terjadi setelah mengikuti suatu proses pembelajaran, baik berupa nilai atau pun tingkahlaku. maksudnya perubahan tersebut adalah, perubahan yang positif terhadap diri siswa seperti tidak tahu menjadi tahu, tidak mengerti menjadi mengerti, tidak baik menjadi baik, serta mampu membedakan antara hak dan bathil juga mengamalkan dalam kehidupan sehari-hari. Namun realita yang terjadi begitu banyak siswa, yang tidak mengerti dengan apa yang ia pelajari,contohnya masih banyak siswa yang melanggar perintah Allah SWT,dan mengerjakan larangan Allah SWT.

Bukan hanya itu, tetapi juga masalah besar yang dihadapai oleh pendidikan nasional antara lain persoalan mutu, relevansi efektivitas dan efesiensi 
pendidikan. Masalah-masalah ini menimbulkan keresahan pada masyarakat yang seringkali terdengar dalam diskusi-diskusi, seminar-seminar, lokakarya dan terbaca dalam surat kabar, majalah-majalah, jurnal-jurnal, dan sebagainya. ${ }^{1}$ Keresahan tersebut (bahwa pendidikan kita masih rendah mutunya), kurang relevansinya dengan kebutuhan pembangunan, kurang efektif dan efesien pelaksanaannya, ini harus segera ditanggapi secara serius dan dipecahkan secara komprehensif dan terpadu, demi suksesnya pendidikan yang juga berarti pembangunan bangsa. $^{2}$ Salah satu mutu pendidikan yang harus ditingkatkan adalah tenaga pendidik (Guru) yang berkaitan dengan metode mengajar. Metode mengajar yang kurang baik akan memperngaruhi hasil belajar siswa sesuai dengan tujuan pendidikan baik pendidikan umum maupun agama.

Dalam pelaksanaan proses belajar mengajar guru tidak menggunakan metode yang khas dan menarik. Guru hanya menggunakan satu metode yaitu metode ceramah, ketika menyampaikan materi guru tidak memperhatikan kedidiplinan siswa dalam mengikuti pembelajaran, juga tidak menanyakan kepamahaman siswa dan tidak mengevaluasi siswa setelah proses pembelajaran berlangsung.

Di dalam UUSPN No.2/1989 pasal 29 ayat (2) ditegaskan bahwa isi kurikulum setiap jenis jalur dan jenjang pendidikan wajib memuat antara lain Pendidikan Agama. Dan dalam penjelasannya dinyatakan bahwa Pendidikan Agama merupakan usaha untuk memperkuat iman dan ketaqwaan terhadap Tuhan Yang Maha Esa sesuai dengan agama yang dianut oleh peserta didik yang bersangkutan dengan memperhatikan tuntutan untuk menghormati agama lain dalam hubungan kerukunan antar umat beragama dalam masyarakat untuk mewujudkan persatuan nasionsal. ${ }^{3}$

Pendidikan Agama Islam adalah upaya sadar dan terencana dalam menyiapkan peserta didik untuk mengenal, memahami, menghayati hingga mengimani, bertaqwa dan berakhlak mulia dalam mengamalkan ajaran Agama

\footnotetext{
1 Abdul Majid, Belajar dan Pembelajaran Pendidikan Agama Islam, (Bandung: PT Remaja Rosdakarya, 2012), h, 1.

${ }^{2}$ Ibid., h, 1.

${ }^{3}$ Muhaimin, Paradigma Pendidikan Islam, (Bandung: Remaja Rosdakarya, 2012), h, 75 .
} 
Islam dari sumber utamanya kitab suci Al-Qur'an dan Hadits melalui bimbingan, pengajaran, latihan, serta penggunaan pengalaman. ${ }^{4}$

Tujuan Pendidikan Agama Islam di Sekolah atau Madrasah bertujuan untuk menumbuhkan dan meningkatkan keimanan melalui pemberian dan pemupukan pengetahuan, penghayatan, serta pengalaman peserta didik tentang agama Islam sehingga menjadi manusia muslim yang terus berkembang dalam hal keimanan, ketaqwaan-Nya, berbangsa dan bernegara serta untuk dapat melanjutkan pada jenjang pendidikan yang lebih tinggi. ${ }^{5}$ Salah satu alat untuk mencapai tujuan Pendidikan Agama Islam di Sekolah atau Madrasah yaitu melalui metode yang efektif. Metode adalah tehnik atau cara penyajian yang dikuasai guru untuk mengajar atau menyajikan bahan pelajaran kepada siswa di dalam kelas baik secara individual maupun secara kelompok atau klasikal agar pelajaran tersebut dapat diterima, dipahami, dan dimanfaatkan oleh siswa dengan baik. ${ }^{6}$

Adapun metode yang efektif yang harus dilakukan guru agar tercapainya tujuan Pendidikan Agama Islam adalah metode Targhib-Tarhib. Metode TarghibTarhib adalah strategi atau cara untuk meyakinkan seorang murid terhadap kekuasaan dan kebenaran Allah SWT melalui janji-Nya disertai dengan bujukan dan rayuan untuk melakukan amal shaleh. ${ }^{7}$ Metode Targhib-Tarhib merupakan metode yang dapat meningkatkan hasil belajar siswa. Menurut Ahmad Susanto Hasil belajar yaitu perubahan-perubahan yang terjadi pada diri siswa, baik yang menyangkut aspek kognitif, afektif, dan psikomotor sebagai hasil dari kegiatan belajar. ${ }^{8}$

Senada dengan Syaiful Bahri Djamarah belajar adalah serangkaian kegiatan jiwa raga untuk memperoleh suatu perubahan tingkah laku sebagai hasil dari pengalaman individu dalam interaksi dengan lingkungannya yang menyangkut kognitif, afektif, dan psikomotor. ${ }^{9}$ Sedangkan menurut Rosleni Marliany bahwa

\footnotetext{
${ }^{4}$ Abdul Majid, Op.Cit., h, 11.

${ }^{5}$ Ibid., h, 16.

${ }^{6}$ Abu Ahmadi dan Joko Tri Prasetya, Strategi Belajar Mengajar, (Bandung: CV. Pusaka Setia, 1997), h, 52.

7 Heri Jauhari Muchtar, Fikih Pendidikan, (Bandung: PT Remaja Rosdakarya, 2005), h, 221-222.

${ }^{8}$ Ahmad Susanto, Teori Balajar dan Pembelajaran, (Jakarta: 2014), Cet ke-2, h. 5

${ }^{9}$ Syaiful Bahri Djamarah, Psikologi Belajar,(Jakarta : Rineka Cipta, 2011), h, 13.
} 
Belajar dapat didefinisikan sebagai perubahan yang relatif permanen pada prilaku yang terjadi akibat latihan. ${ }^{10}$

Dari beberapa pendapat diatas dapat disimpulkan bahwa hasil belajar adalah perubahan yang terjadi akibat dari latihan, baik kegiatan jiwa maupun raga yang menyangkut kognitif, afektif, dan psikomotor. Ciri-ciri hasil belajar yaitu bodoh menjadi pintar, Merangkak menjadi berdiri, berdiri menjadi berjalan, berjalan menjadi berlari, hafal menjadi mengerti, mengerti menjadi faham, faham menjadi cerdas,gagap menjadi terampil, Pasif menjadi aktif. ${ }^{11}$

\section{METODE PENELITIAN}

Jenis penelitian menggunakan pendekatan deskriptif kualitatif yang penulis gunakan adalah library research yaitu mengumpulkan buku-buku yang berkaitan dengan objek penelitian atau penelitian yang bersifat kepustakaan.

1. Sumber Data

Kajian yang penulis gunakan adalah penelitian perpustakaan murni, penulis akan menggunakan dua sumber, yaitu:

a. Sumber Primer

Sumber data yang berifat primer adalah buku rujukan awal dan utama dalam penelitian, sumber primer yang penulis gunakan adalah :

i. Syahidin, Menelusuri Metode Pendidikan Dalam Al-Qur'an, (Bandung: Alfabeta. 2009)

ii. Syaiful Bahri Djamarah, Psikologi Belajar, (Jakarta : Rineka Cipta, 2011)

iii. Heri Jauhari Muchtar, Fikih Pendidikan, (Bandung: PT Remaja Rosdakarya, 2005)

iv. Ahmad Tafsir, Ilmu Pendidikan Dalam Perspektif Islam, (Bandung: PT Remaja Rosdakarya, 1992)

v. Abu Ahmadi,dan Joko Tri Prasetya, Strategi Belajar Mengajar, (Bandung: CV. Pusaka Setia, 1997)

${ }^{10}$ Rosleny Marliany, Psikologi Umum, (Bandung: Pustaka Setia, 2010), h, 195.

${ }^{11} \mathrm{Ibid}, \mathrm{h}, 197$. 
b. Sumber Sekunder

Sumber sekunder adalah hasil pengumpulan yang dilakukan oleh orang lain dengan maksud tertentu dan mempunyai kategori atau klasifikasi menurut keperluan masing-masing dan kegunaan bagi peneliti masingmasing. ${ }^{12}$ Dalam hal ini Sumber data yang berifat sekunder adalah buku rujukan pendukung dalam penelitian, sumber sekunder yang penulis gunakan adalah :

i. Abdul Majid, Belajar dan Pembelajaran Pendidikan Agama Islam, Bandun: PT Remaja Rosdakarya, 2012)

ii. Abu Ahmadi dan Joko Tri Prasetya,Strategi Belajar Mengajar, Bandung: CV. Pusaka Setia, 1997)

iii. Aprilia Kumala, Dan Arundaya, Kamus Bahasa Bahasa Indonesia, Surabaya: Ikhtiar, th.

iv. Abdurrahman An-nahlawi, Pendidikan Islam Di rumah Sekolah dan Masyarakat, (Jakarta:Gema Insani Press,1995)

v. Departemen Agama Republik Indonesia, Al-Qur'an dan terjemahnya, (Surabaya: Karya Agung, 2006)

vi. Nur Uhbiyati, Ilmu Pendidikan Islam (IPI) Untuk UIN-STAI-PTAIS Fakultas Tarbiyah Komponen MKDK, (Bandung: Pustaka Setia, 1997)

vii. Rosleny Marliany, Psikologi Umum, (Bandung: Pustaka Setia, 2010)

\section{Teknik Pengumpulan Data}

Teknik pengumpulan data adalah cara-cara yang digunakan oleh peneliti untuk mengumpulkan data. ${ }^{13}$ Pengumpulan data dalam penelitian ini adalah dengan cara dokumentasi. Dokumentasi adalah "ditujukan untuk memperoleh data langsung dari tempat penelitian, meliputi buku-

${ }^{12}$ S. Nasotion, Metode Research Penelitian Ilmiah, (Jakarta: Bumi Aksara, 2002), Cet. 5 , h. 143

13 Riduwan, Skala Pengukuran Variabel-Variabel Penelitian, (Bandung: Alfabeta, 2013), Cet. Ke-10, h. 24 
buku yang relevan, peraturan-peraturan, laporan kegiatan, foto-foto, fim, dokumenter, data yang relevan penelitian". ${ }^{14}$

3. Teknik Analisa Data

Teknik analisa data adalah cara penghitungan untuk menjawab rumusan masalah dan pengujian hipotesis yang diajukan. ${ }^{15}$ Hipotesis adalah jawaban sementara yang harus di uji kebenarannya. Namun, penelitian yang penulis gunakan dengan kajian pustaka (library research) ini, maka penulis menggunakan tekhnik analisa data kajian isi (countent analysis).

Kajian ini adalah kajian yang menanfaatkan buku atau dokumen untuk menarik kesimpulan, baik kajian isi yang bersifat deduktif maupun kajian isi yang bersifat induktif. ${ }^{16}$ Pada kajian ini peneliti terlebih dahulu mengadakan survei data untuk memperoleh informasi dari penelitian terdahulu terhadap pengerjaan tanpa memperdulikan apakah data itu primer atau sekunder, di lapangan atau dilaboratorium. Kemudian, menelusuri leteratur yang ada serta mentelaahnya secara tekun. Setelah itu, peneliti mengungkapkan buah pikiran secara kritis dan analistis. ${ }^{17}$

\section{PEMBAHASAN}

Metode adalah cara yang telah diatur dan berfikir baik-baik untuk mencapai suatu maksud dalam ilmu pengetahuan dan sebagainya cara belajar dan sebagainya. ${ }^{18}$ Menurut Muhibbin Syah metode secara harfiah berarti "cara". Dalam pemakaian umum metode diartikan sebagai cara melakukan suatu kegiatan atau cara mekakukan pekerjaan dengan menggunakan fakta dan konsep-konsep secara sistematis. ${ }^{19}$

${ }^{14}$ Ibid., h. 31

15 Riduan, Belajar Mudah Penelitian Untuk Guru, Karyawan Dan Peneliti Pemula, (Bandung: Alfabeta, 2015). h. 12

${ }^{16}$ Lexy J. Moleong, Metodologi Penelitian Kualitatif (Bandung:Remaja Rosdakarya, 2013), Cet. 31, h. 220

${ }^{17}$ Moh. Nazir, Metode Penelitian, (Bogor Selatan: Ghalia Indonesia, 2005), h. 93 Ikhtiar,)tth h,283

${ }^{18}$ Aprilia Kumala, Dan Arundaya, Kamus Bahasa Bahasa Indonesia, (Surabaya:

${ }^{19}$ Muhibbin Syah, Psikologi Pendidikan dengan Pendekatan Baru, (Bandung: Remaja Rosdakarya, 2008), h, 201. 
Sedangkan menurut Departemen Agama RI metode adalah cara yang digunakan Guru untuk menyampaikan pelajaran kepada pelajar. ${ }^{20}$ Senada dengan Abu Ahmadi dan Joko Tri Prasetya Metode adalah tehnik atau cara penyajian yang dikuasai guru untuk mengajar atau menyajikan bahan pelajaran kepada siswa di dalam kelas baik secara individual maupun secara kelompok atau klasikal agar pelajaran tersebut dapat diterima, dipahami, dan dimanfaatkan oleh siswa dengan baik. $^{21}$

Berdasarkan teori di atas dapat disimpulkan bahwa metode adalah cara melakukan suatu kegiatan atau cara melakukan pekerjaan dengan menggunakan fakta dan konsep-konsep secara sistematis yang digunakan guru untuk menyampaikan pelajaran kepada pelajar di dalam kelas, baik secara individual maupun secara kelompok atau klasikal agar pelajaran tersebut dapat diterima, dipahami, dan dimanfaatkan oleh siswa dengan baik. Menurut Abdurrahman Annahlawi Targhib adalah janji yang desertai bujukan dan dan rayuan untuk menunda kemaslahatan kelezatan dan kenikmatan. Tarhib adalah ancaman atau intimidasi melalui hukuman yang disebabkan oleh terlaksananya sebuah dosa, kesalahan, atau perbuatan yang telah dilarang Allah SWT. ${ }^{22}$ Senada dengan Ahmad Tafsir Targhib ialah janji terhadap kesenangan dan kenikmatan akhirat yang disertai bujukan. Sedangkan Tarhib ialah Ancaman karena dosa yang dilakukan. ${ }^{23}$ Menurut An-ahlawi sebagaimana dikutip oleh Syahidin bahwa Targhib adalah janji yang disertai dengan bujukan dan membuat senang terhadap sesuatu yang mashlahat terhadap kenikmatan atau kesenangan akhirat yang baik dan pasti serta bersih dari segala kotoran yang kemudian diteruskan dengan melakukan amal shaleh dan menjauhi kenikmatan selintas yang mengandung bahaya dan perbuatan buruk. $^{24}$

\footnotetext{
${ }^{20}$ Departemen Agama RI, Metodologi Pendidikan Agama Islam, (Jakarta: Direktor Jendral Kelembagaan Agama Islam,2002), h, 88.

${ }^{21}$ Abu Ahmadi, dan Joko Tri Prasetya, Strategi Belajar Mengajar, (Bandung: CV. Pusaka Setia, 1997) h, 52.

${ }^{22}$ Abdurrahman An-nahlawi, Pendidikan Islam Di rumah Sekolah dan Masyarakat, (Jakarta:Gema Insani Press, 1995), h, 296

${ }^{23}$ Ahmad Tafsir, Ilmu Pendidikan Dalam Perspektif Islam, (Bandung: PT Remaja Rosdakarya, 1992), h, 146. 2009)h, 125.

${ }^{24}$ Syahidin, Menelusuri Metode Pendidikan Dalam Al-Qur'an, (Bandung: Alfabeta,
} 
Sementara Tarhib adalah suatu ancaman atau siksaan sebagai akibat melakukan dosa atau kesalahan yang dilarang Allah SWT atau akibat lengah dalam menjalankan kewajiban yang diperintahkan Allah SWT. ${ }^{25}$ Senada dengan Ramayulis Targhib ialah janji terhadap kesenangan dan kenikmatan akhirat yang disertai bujukan. Tarhib ialah ancaman karna dosa yang dilakukan. ${ }^{26}$

Sedangkan menurut Heri Jauhari Muchtar Targhib adalah strategi atau cara untuk meyakinkan seseorang murid terhadap kekuasaan dan kebenaran Allah SWT melalui janji-janji-Nya disertai dengan bujukan dan rayuan untuk melakukan amal shaleh. Adapun Tarhib adalah strategi untuk meyakinkan seseorang murid terhadap kekuasaan dan kebenaran Allah SWT melalui ancaman dan siksaan sebagai akibat melakukan perbuatan yang dilarang Allah SWT. ${ }^{27}$

Berdasarkan pendapat di atas dapat disimpulkan bahwa yang dimaksud dengan Targhib adalah strategi atau cara untuk menyakinkan seseorang terhadap kebenaran Allah SWT melalui janji-Nya yang disertai dengan bujukan ganjaran yang berupa pemberian barang dan rayuan untuk melakukan amal shaleh. Adapun metode Targhib - Tarhib yaitu cara memberikan pelajaran dengan memberi dorongan (motivasi) untuk memperoleh kegembiraan bila mendapatkan sukses dalam kebaikan, sedang bila tidak sukses karena tidak mau mengikuti petunjuk yang benar akan mendapat kesusahan. ${ }^{28}$

\section{Bentuk-Bentuk Targhib-Tarhib}

Penggunaan Metode Targhib-Tarhib didasarkan pada asumsi bahwa tingkatan kesadaran manusia itu berbeda-beda. Disatu pihak ada orang yang sadar hanya melalui nasehat atau teladan yang baik tetapi ada pula orang yang tidak bisa tersadarkan kecuali harus dirangsang atau diancam. ${ }^{29}$

1. Bentuk Targhib (Rangsangan)

\footnotetext{
${ }^{25}$ Ibid., h, 125.

${ }^{26}$ Rama Yulis, Metodologi Pendidikan Agama Islam, (Jakarta: Kalam Mulia, 2014), h, 439.

${ }^{27}$ Heri Jauhari Muktar, Fikih Pendidikan, (Bandung: PT Remaja Rosdakarya, 2005) h, 222.

${ }^{28}$ Nur Uhbiyati, Ilmu Pendidikan Islam (IPI) Untuk UIN-STAI-PTAIS Fakultas Tarbiyah Komponen MKDK, (Bandung: Pustaka Setia, 1997), h, 122.

${ }^{29}$ Syahidin, Op. Cit., hal, 127.
} 
a. Dijanjikan bahwa Allah SWT akan mencintai orang-orang senantiasa berbuat kebaikan. Firman Allah SWT :

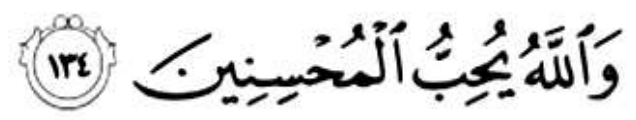

Artinya: "Dan Allah SWT mencintai orang-orang yang senantiasa berbuat kebaikan" (Q.S. Ali Imran: (134) ${ }^{30}$

b. Dijanjikan akan memperoleh kebahagiaan didunia; (QS. Yunus: 63-64).

c. Dijanjikan akan mendapatkan kenikmatan langsung dirasakan didunia. ${ }^{31}$

d. Mendapat jaminan syurga.

e. Dijanjikan akan mendapat pengampunan Allah SWT. ${ }^{32}$

2. Bentuk Tarhib (Ancaman)

1. Ancaman tidak akan mendapat ridho dari Allah SWT.

2. Diancam akan diperangi oleh Allah SWT dan Rasul-Nya. ${ }^{33}$

3. Diancam hukuman dunia.Firman Allah SWT:

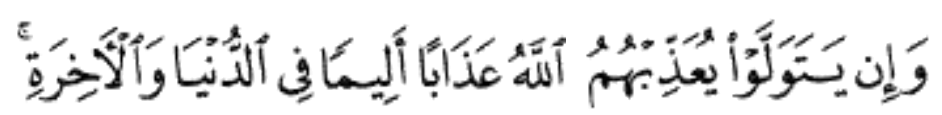

Artinya "Bila mereka tidak patuh, maka Allah SWT akan menghukum mereka dengan hukuman yang pedih didunia dan akhirat”. (Q.S.AlTaubah [9]:74). ${ }^{34}$

4. Mendapatkan siksaan langsung didunia.

5. Diancam hukuman neraka. ${ }^{35}$

Adapun keistimewaan metode ini adalah sebagai berikut: Targhib - Tarhib lebih teguh karena akarnya berada di langit (transeden). Metode ini pertama kali diperkenalkan oleh Abdurrahman an-Nahlawi,Guru Besar Tarbiyah pada Universitasal-Azhar, Kairo, Mesir. Lahir pada tanggal 7 Safar 1396 H / 1876 M di sebuah daerah bernama Nahlawa Kota Madinah Saudi Arabia.

Secara operasional Targhib dan Tarhib lebih mudah dilaksanakan dari pada metode hukuman dan ganjaran karena materi Targhib dan Tarhib sudah ada

\footnotetext{
${ }^{30}$ Departemen Agama Republik Indonesia, Al-Qur'an dan terjemahnya, (Surabaya: Karya Agung, 2006), h, 84.

${ }^{31}$ Heri Jauhari Muchtar, Op.Cit., h, 222.

${ }^{32}$ Ibid., h, 222.

${ }^{33}$ Syahidin, Op.Cit., h, 130.

${ }^{34}$ Departemen Agama Republik Indonesia, Op.Cit, h,267.

${ }^{35}$ Syahidin, Op.Cit., h, 130-131.
} 
dalam Al-Qur'an dan Hadits Nabi. Targhib dan Tarhib lebih universal dapat digunakan kepada siapa saja dan dimana saja. ${ }^{36}$

\section{Langkah-langkah Metode Targhib-Tarhib}

Menurut Syahidin Adapun langkah-langkah dalam mengaplikasikan Metode Targhib dan Tarhib ini adalah sebagai berikut:

1. Mengungkapkan ganjaran-ganjaran alamiah terhadap orang mentaati perintah Allah SWT.

2. Menguraikan hukuman-hukuman alamiah terhadap pelaku dosa.

3. Membacakan dan menerjemahkan ayat-ayat Al-Qur'an atau Hadits yang berkenaan dengan Targhib dan Tarhib, kemudian menjelaskan ayat-ayat AlQur'an dan Hadits yang mengandung Targhib dan Tarhib.

4. Memotivasi murid untuk mendiskusikan ayat-ayat Al-Quran dan Hadits yang mengandung Targhib dan Tarhib. ${ }^{37}$

5. Memberikan gambaran kebahagiaan di akhirat (Surga) bagi orang yang mengamalkan perintah Allah SWT dan menjauhi larangan-Nya seperti menegakkan shalat dan membayar zakat, menjauhi perbuatan zina dan sebagainya.

6. Memberikan gambaran kesengsaraan di akhirat (Neraka) bagi orang yang melalaikan perintah Allah SWT atau melanggar larangan-Nya seperti meninggalkan shalat dan tidak mengeluarkan zakat atau berbuat zina, dan sebagainya.

7. Meminta salah seorang siswa untuk mengungkapkan pesan dan sikapnya terhadap pokok materi pelajaran yang baru disajikan. ${ }^{38}$

Sedangkan menurut Heri Jauhari Muchtar Adapun langkah-langkah dalam mengaplikasikan Metode Targhib dan Tarhib ini adalah sebagai berikut:

1. Jangan menghukum ketika marah. Karena pemberian hukuman ketika marah akan lebih bersifat emosional yang dipengaruhi nafsu syaithaniyah. ${ }^{39}$

${ }^{36}$ Ibid., h, 439-440.

${ }^{37}$ Syahidin, Op.Cit., h, 132-133.

${ }^{38}$ Ibid., h, 133.

${ }^{39}$ Heri Jauhari Muchtar, Op.Cit., h, 21. 
2. Jangan sampai menyakiti perasaan dan harga diri anak atau orang yang kita hukum.

3. Jangan sampai merendahkan derajat dan martabat orang bersangkutan.

4. Jangan menyakiti secara fisik.

5. Bertujuan mengubah perilakunya yang kurang atau tidak baik. ${ }^{40}$

Selanjutnya menurut Abdurrahman An-Nahlawi Adapun langkah-langkah dalam mengaplikasikan Metode Targhib dan Tarhib ini adalah sebagai berikut:

1. Kewajiban manusia untuk menanamkan keimanan dan akidah yang shahih dalam diri anak didik sehingga mereka mudah memahami syarat masuk surga dan menghindari hal-hal yang dapat menjerumuskan manusia pada azab Allah SWT.

2. Seorang pendidik dituntut untuk pandai-pandai memilih imajinasi dan konsep Qur'ani dan Nabawi yang tepat dalam menyajikan materi tentang pahala dan azab Allah SWT.

3. Pengobaran emosi dan pembinaan afeksi ketuhanan.

4. Pengontrolan emosi, afeksi, dan keseimbangan keduanya.

\section{Perbandingan antara Targhib-Tarhib dangan reward and punishment}

Adapun perbandingan antara Targhib - Tarhib dalam pendidikan Islam dengan Reward and Punishment dalam pendidikan barat, kalau diteliti lebih jauh maka sangat nampak perbedaannya. Perbedaan itu dapat dilihat dari metode dan datangnya teori itu sendiri.perbedaan antara Targhib - Tarhib dengan Reward and Punishment itu antara lain :

1. Targhib - Tarhib bersifat Transenden yang datangnya langsung dari (Langit) dari Allah SWT yang diturunkan ( diwahyukan ) kepada Nabi Muhammad SAW, yang kemudian disampaikan kepada Ummat manusia. Yang dalam hal ini Targhib - Tarhib dapat dan mampu mempengaruhi peserta didik secara fitri. Semua ayat-ayat yang diwahyukan oleh Allah SWT kepada Nabi muhammad SAW yang mengandung Targhib - Tarhib ini mempunyai syarat kepada keimanan kepada Allah SWT,dan hari akhir. Sedangkan taori dan metode Reward and Punishment, itu hasil pemikiran manusia yang tentu hanya

\footnotetext{
${ }^{40}$ Ibid., h, 21-22.
} 
berdasarkan teori-teori yang berdasarkan pemikiran-pemikiran manusia yang bisa saja salah dan pada waktu tertentu tidak relevan lagi.

2. Targhi-tarhib disertai dengan gambaran-gambaran yang indah tentang kenikmatan surga atau dahsyatnya neraka. Dengan ketentuan kalau baik dan mengikuti perintah Allah SWT akan mendapatkan Surga, sebaliknya kalau berbuat kejahatan, maka balasannya adalah neraka. Sedangkan reward and punishment hadiah nyata yang sifatnya sementara, dengan ketentuan kalau peserta didik rajin,disiplin,taat aturan, maka langsung diberikan hadiah berupa penghargaan dan hadiah berupa materi. Tapi kalau peserta didik melakukan kesalahan,bandel,malas dan tidak mengikuti aturan yang berlaku, maka akan mendapat hukuman dan sanksi lainnya .

3. Targhib-Tarhib menggugah serta mendidik perasaan Rabbaniyah,seprti khauf,khusu' raja' dan cinta kepada Allah SWT. Sedangkan reward and punishment hanya terfokus kepada taat aturan, takut kepada pimpinan atau guru.

4. Targhib-Tarhib mempunyai keseimbangan antara kean dan perasaan terhadap akan ampunan dan rahmat Allah SWT, sedangkan reward and punishment berharap kasih sayang dan ampunan dari manusia yang membuat aturan.

\section{KESIMPULAN}

Metode Targhib-Tarhib adalah strategi atau cara untuk meyakinkan seorang murid terhadap kekuasaan dan kebenaran Allah SWT melalui janji-Nya disertai dengan bujukan dan rayuan untuk melakukan amal shaleh. Selanjutnya menurut Abdurrahman An-Nahlawi langkah-langkah dalam Metode Targhib dan Tarhib ini adalah: (1). Kewajiban manusia untuk menanamkan keimanan dan akidah yang shahih dalam diri anak didik sehingga mereka mudah memahami syarat masuk surga dan menghindari hal-hal yang dapat menjerumuskan manusia pada azab Allah SWT. (2). Pendidik dituntut untuk pandai-pandai memilih imajinasi dan konsep Qur'ani dan Nabawi yang tepat dalam menyajikan materi tentang pahala dan azab Allah SWT. (3). Mendidik Pengobaran emosi dan pembinaan afeksi ketuhanan. (4). Pengontrolan emosi, afeksi, dan keseimbangan keduanya. 
Dengan penerapan metode Targhib-Tarhib ini harapan dapat terciptanya peserta didik beriman dan bertaqwa kepada Allah SWT, terciptanya peserta didik berakhlaqul karimah baik di rumah, sekolah maupun di lingkungannya, terciptanya peserta didik patuh dan taat kepada orang tua, Guru, dan masyarakat, terciptanya peserta didik yang aktit, optimis dan hilangkan rasa malas dalam proses pembelajaran, terciptanya kognitif, Afektif dan psikomotor pada peserta didik sesuai harapan.

\section{DAFTAR PUSTAKA}

Abdul Majid, Belajar dan Pembelajaran Pendidikan Agama Islam, (Bandung: PT Remaja Rosdakarya, 2012)

Abu Ahmadi dan Joko Tri Prasetya,Strategi Belajar Mengajar, (Bandung: CV. Pusaka Setia, 1997)

Ahmad Susanto, Teori Balajar dan Pembelajaran, (Jakarta: Cet, Ke-2 2014)

Aprilia Kumala, Dan Arundaya, Kamus Bahasa Bahasa Indonesia, (Surabaya: Ikhtiar, tth)

Abu Ahmadi,dan Joko Tri Prasetya.Strategi Belajar Mengajar. Bandung: CV. Pusaka Setia, 1997.

Abdurrahman An-nahlawi, Pendidikan Islam Di rumah Sekolah dan Masyarakat, (Jakarta:Gema Insani Press,1995)

Ahmad Tafsir, Ilmu Pendidikan Dalam Perspektif Islam, (Bandung: PT Remaja Rosdakarya, 1992)

Departemen Agama RI, Metodologi Pendidikan Agama Islam, (Jakarta: Direktor Jendral Kelembagaan Agama Islam,2002)

Departemen Agama Republik Indonesia, Al-Qur'an dan terjemahnya, (Surabaya: Karya Agung, 2006)

Heri Jauhari Muchtar, Fikih Pendidikan, (Bandung: PT Remaja Rosdakarya, 2005)

Lexy J. Moleong, Metodologi Penelitian Kualitatif (Bandung:Remaja Rosdakarya, 2013), Cet. 31

Muhaimin, Paradigma Pendidikan Islam, (Bandung: Remaja Rosdakarya, 2012) 
Muhibbin Syah, Psikologi Pendidikan dengan Pendekatan Baru, (Bandung: Remaja Rosdakarya, 2008)

Moh. Nazir, Metode Penelitian, (Bogor Selatan: Ghalia Indonesia, 2005)

Nur Uhbiyati, Ilmu Pendidikan Islam (IPI) Untuk UIN-STAI-PTAIS Fakultas Tarbiyah Komponen MKDK, (Bandung: Pustaka Setia, 1997)

Rosleny Marliany, Psikologi Umum, (Bandung: Pustaka Setia, 2010)

Riduwan, Skala Pengukuran Variabel-Variabel Penelitian, (Bandung: Alfabeta, 2013), Cet. Ke-10

Riduan, Belajar Mudah Penelitian Untuk Guru, Karyawan Dan Peneliti Pemula, (Bandung: Alfabeta, 2015)

Rama Yulis, Metodologi Pendidikan Agama Islam, (Jakarta: Kalam Mulia, 2014)

Syahidin, Menelusuri Metode Pendidikan Dalam Al-Qur'an, (Bandung: Alfabeta. 2009)

Syaiful Bahri Djamarah, Psikologi Belajar, (Jakarta : Rineka Cipta, 2011)

S. Nasotion, Metode Research Penelitian Ilmiah, (Jakarta: Bumi Aksara, 2002), Cet. 5 